\title{
Editorial: Impact of Early Life Nutrition on Immune System Development and Related Health Outcomes in Later Life
}

\begin{abstract}
Laxmi Yeruva ${ }^{1,2,3^{*}}$, Daniel Munblit ${ }^{4,5,6}$ and Maria Carmen Collado ${ }^{7}$
${ }^{1}$ Arkansas Children's Nutrition Center, Little Rock, AR, United States, ${ }^{2}$ Department of Pediatrics, University of Arkansas for Medical Sciences, Little Rock, AR, United States, ${ }^{3}$ Arkansas Children's Research Institute, Little Rock, AR, United States,

${ }^{4}$ Department of Pediatrics and Pediatric Infectious Diseases, Institute of Child's Health, Sechenov First Moscow State Medical University (Sechenov University), Moscow, Russia, ${ }^{5}$ Inflammation, Repair and Development Section, National Heart and Lung Institute, Faculty of Medicine, Imperial College London, London, United Kingdom, ${ }^{6}$ Solov'ev Research and Clinical Center for Neuropsychiatry, Moscow, Russia, 7 Department of Biotechnology, Unit of Lactic Acid Bacteria and Probiotics, Institute of Agrochemistry and Food Technology, National Research Council (IATA-CSIC), Valencia, Spain
\end{abstract}

Keywords: human milk, immunity, infants, metabolites, human milk oligosaccharides, microRNAs, microbiota, allergy

\section{OPEN ACCESS}

Edited by:

Willem Van Eden,

Utrecht University, Netherlands

Reviewed by:

Martijn Van Herwijnen, Utrecht University, Netherlands

*Correspondence:

Laxmi Yeruva

vlyeruva@uams.edu

Specialty section: This article was submitted to Nutritional Immunology, a section of the journal

Frontiers in Immunology

Received: 16 February 2021 Accepted: 11 March 2021 Published: 25 March 2021

Citation:

Yeruva L, Munblit D and Collado $M C$ (2021) Editorial: Impact of Early Life

Nutrition on Immune System

Development and Related Health

Outcomes in Later Life.

Front. Immunol. 12:668569.

doi: 10.3389/fimmu.2021.668569
Editorial on the Research Topic

Impact of Early Life Nutrition on Immune System Development and Related Health Outcomes in Later Life

\section{EARLY LIFE NUTRITION AND HEALTH OUTCOMES IN LATER LIFE}

Human milk (HM) is a complex mixture of macronutrients and bioactive compounds that provide optimal nutrition to infants (1-5). HM has been shown to impact infant's gastro-intestinal tract, immune system, microbiota composition, metabolism and also may have long-term effects on the development of infectious and non-communicable diseases $(3,6-8)$. The aim of this editorial is to provide a summary of the original research, reviews and opinions regarding key factors affecting human milk composition, and the role of bioactive components of human milk on infants' health.

Maternal obesity and maternal atopy are highly prevalent states that may have an effect on HM composition and infants' health outcomes (9-14). Few studies, however, have attempted to evaluate associations between HM metabolome composition and measures of infants' health and development. For instance, Bardanzellu et al. reviewed different studies for HM metabolite profile from mothers with overweight and obesity in an attempt to determine the milk metabolome composition with respect to obesity. However, the small sample size and large variability of the measures precluded the investigators from drawing conclusions which underscores the necessity of large sample size studies in this area of research. The authors, however, found that the fatty acid profile of human milk was associated with the maternal obesity status. Specifically, higher levels of saturated fatty acids and lower levels of monounsaturated and n-3 long-chain polyunsaturated fatty acids were found in milk of women with obesity compared to milk of women with normal weight. These changes in milk composition may influence long-term weight gain and glucose tolerance, in infants. 
Allergic diseases are of a major concern and a significant burden to healthcare. It has been previously shown that HM composition may differ in allergic and non-allergic mothers (15). Recent research from Stinson et al. demonstrated that human milk from atopic mothers had lower levels of short-chain fatty acids (SCFA). Importantly, reduced levels of SCFA during early life may program the gut, microbiota, and obesity in infants. Nutritional interventions during pregnancy and lactation could serve as strategies to mitigate maternal atopy and potentially improve HM composition. For instance, Kao et al. showed that maternal consumption of goat milk during pregnancy and lactation associated with reduced airway inflammation and allergy outcomes in the offspring compared to cow's milk consumption. The goat milk feeding had increased immunoglobulin levels, Th1 cytokine production, and improved NK cell activity in comparison to cow' milk feeding in the offspring. In addition, in an animal study by Adel-Patient et al. showed that altering maternal immune status by sensitizing to different antigens protects offspring by modulating the antibody composition of human milk to specific antigens. In summary, obesity and prenatal antigen exposure of mothers were associated with HM composition and may affect infant health and development, but relationships should be confirmed in methodologically rigorous studies with a large sample size.

Human milk feeding likely protects from pathogens, thereby reducing/preventing negative outcomes associated with infection via different bioactives of milk such as human milk oligosaccharides (HMOs) and free amino acids (FAAs) (1, 1619). Indeed, Carr et al. review highlighted the antipathogenic and immunomodulatory properties of HMOs and Zuurveld et al. reviewed the potential role of HMOs in preventing allergic diseases. In their article Sadelhoff et al., discuss the potential role of amino acids (particularly glutamine and glutamate) in $\mathrm{HM}$ to protect against neonatal allergies and infection. Further, using a HM-fed piglet model, Rosa et al. demonstrated the appearance of HM metabolites' in the gut, serum, and urine of HM-fed piglets. Importantly, glutamic acid and glutamate levels were higher in the HM-fed animals relative to the formula fed group suggesting potential benefits of HM FAAs. Also, Rosa et al., study discussed human metabolites such as polyamines and tryptophan impact on immune response.

Human milk has been shown to promote gut microbiota development and function (20-25). In reviewing the literature, Carr et al. comprehensively overviewed the role of $\mathrm{HM}$ microbiota on gut microbiota colonization and immune function. This article also discussed the role of human milk components such as HMOs, and IgA impact on gut microbiota. Peroni et al. reviewed the literature regarding microbiome composition and its impact on the development of allergic diseases. Drall et al. demonstrated an association of microbiota composition in exclusively breastfed infants to $C$. difficile colonization. In summary, dietary intake and both pre- and post-natal factors appear to be associated with the gut microbiota composition and its association to pathogens colonization. This may be a focus for the future intervention strategies aiming at improving infants health.

Previous studies suggest antipathogenic effects of HM components and that the addition of these bioactive molecules (i.e., HMOs, lactoferrin, immunoglobulins, and milk fat globule membrane FGM, extracellular vesicles) to infant formulas may benefit child health $(20,26-36)$, although the studies usually lack methodological rigor and outcomes were based on a small sample size. The studies on recombinant immunoglobulins and bioactivity in the digestive tract are limited. Research from Sah et al. provided some evidence that recombinant antibody towards respiratory syncytial virus (RSV) may impact growth and have neutralization activity against the virus across the GI tract. In another study, Nederend et al. demonstrated that bovine immunoglobulin antiviral activity and $\mathrm{T}$ cell response may prevent RSV infection. Interestingly, Adel-Patient et al. found no protection to protein present in cow's milk by feeding the hydrolysates of caseins and Lactobacillus rhamnosus GG protobiotic. Thus, future studies are needed to fully understand the protective effects of immunoglobulins, as well as pre and probiotics, before adding these components to infant formula. The combined effect of different bioactive molecules within the formula on infant health and development also requires further investigation.

Human milk may impart benefits through epigenetic programming influencing long-term health by various mechanisms. van Esch et al. provided an overview on the evidence of maternal nutrition, environmental factors impact on milk composition, and how the different components of milk epigenetically program infants' health and dictate allergy and asthma outcomes in later life. Human milk contains extracellular vesicles with microRNAs (miRNAs) as one of the epigenetic molecules (35). Furthermore, Carr et al. provided evidence that miRNAs known to modulate gene expression were associated with immune function in the human milk-fed group compared to formula diet-fed group in the piglet model. Also, the review by Carr and associates highlighted that miRNAs present in human milk may be associated with a beneficial effect for infants' health and immune system.

Finally, Bilsen and colleagues elegantly show how a networkbased approach that includes evidence from studies to determine the windows of opportunity to shape lifelong health of infants. This can be used to predict the key candidate markers of early life immune development. Human milk is a complex mixture with several bioactive components providing short and long-term health benefits to infants. We sincerely hope that the article's compilation of the Research Topic on human milk will be useful and interesting to the readers and hope that the knowledge gaps highlighted will be considered for future state-of the art research findings.

\section{AUTHOR CONTRIBUTIONS}

All authors listed have made a substantial, direct, and intellectual contribution to the work and approved it for publication.

\section{FUNDING}

LY is supported by USDA-ARS Project 6026-51000-012-06S, and by NIH 1R21AI146521. 


\section{REFERENCES}

1. Andreas NJ, Kampmann B, Mehring Le-Doare K. Human breast milk: A review on its composition and bioactivity. Early Hum Dev (2015) 91(11):62935. doi: 10.1016/j.earlhumdev.2015.08.013

2. Bardanzellu F, Fanos V, Strigini FAL, Artini PG, Peroni DG. Human Breast Milk: Exploring the Linking Ring Among Emerging Components. Front Pediatr (2018) 6(215):1-6. doi: 10.3389/fped.2018.00215

3. Hanson LA. Session 1: Feeding and infant development breast-feeding and immune function. Proc Nutr Soc (2007) 66(3):384-96. doi: 10.1017/ S0029665107005654

4. Hellmuth C, Uhl O, Demmelmair H, Grunewald M, Auricchio R, Castillejo G, et al. The impact of human breast milk components on the infant metabolism. PloS One (2018) 13(6):e0197713-e0197713. doi: 10.1371/journal.pone.0197713

5. Kim SY, Yi DY. Components of human breast milk: from macronutrient to microbiome and microRNA. Clin Exp Pediatr (2020) 63(8):301-9. doi: 10.3345/cep.2020.00059

6. Hanson LA, Korotkova M, Telemo E. Breast-feeding, infant formulas, and the immune system. Ann Allergy Asthma Immunol (2003) 90(6 Suppl 3):59-63. doi: 10.1016/s1081-1206(10)61662-6

7. Kull I, Almqvist C, Lilja G, Pershagen G, Wickman M. Breast-feeding reduces the risk of asthma during the first 4 years of life. J Allergy Clin Immunol (2004) 114(4):755-60. doi: 10.1016/j.jaci.2004.07.036

8. van den Elsen LWJ, Garssen J, Burcelin R, Verhasselt V. Shaping the Gut Microbiota by Breastfeeding: The Gateway to Allergy Prevention? Front Pediatr (2019) 7. doi: 10.3389/fped.2019.00047

9. Bridgman SL, Azad MB, Field CJ, Haqq AM, Becker AB, Mandhane PJ, et al. Fecal Short-Chain Fatty Acid Variations by Breastfeeding Status in Infants at 4 Months: Differences in Relative versus Absolute Concentrations. Front Nutr (2017) 4:11. doi: 10.3389/fnut.2017.00011

10. Isganaitis E, Venditti S, Matthews TJ, Lerin C, Demerath EW, Fields DA. Maternal obesity and the human milk metabolome: associations with infant body composition and postnatal weight gain. Am J Clin Nutr (2019) 110 (1):111-20. doi: 10.1093/ajcn/nqy334

11. Socha P, Grote V, Gruszfeld D, Janas R, Demmelmair H, Closa-Monasterolo $\mathrm{R}$, et al. Milk protein intake, the metabolic-endocrine response, and growth in infancy: data from a randomized clinical trial. Am J Clin Nutr (2011) 94(6 Suppl):1776S-84S. doi: 10.3945/ajcn.110.000596

12. Larsson MW, Lind MV, Laursen RP, Yonemitsu C, Larnkjaer A, Molgaard C, et al. Corrigendum: Human Milk Oligosaccharide Composition Is Associated With Excessive Weight Gain During Exclusive Breastfeeding-An Explorative Study. Front Pediatr (2019) 7:521. doi: 10.3389/fped.2019.00521

13. Lauritzen L, Halkjaer LB, Mikkelsen TB, Olsen SF, Michaelsen KF, Loland L, et al. Fatty acid composition of human milk in atopic Danish mothers. Am J Clin Nutr (2006) 84(1):190-6. doi: 10.1093/ajcn/84.1.190

14. Leghi GE, Netting MJ, Middleton PF, Wlodek ME, Geddes DT, Muhlhausler ABS. The impact of maternal obesity on human milk macronutrient composition: A systematic review and meta-analysis. Nutrients (2020) 12 (4):934. doi: 10.3390/nu12040934

15. Munblit D, Boyle RJ, Warner JO. Factors affecting breast milk composition and potential consequences for development of the allergic phenotype. Clin Exp Allergy (2015) 45(3):583-601. doi: 10.1111/cea.12381

16. Alderete TL, Autran C, Brekke BE, Knight R, Bode L, Goran MI, et al. Associations between human milk oligosaccharides and infant body composition in the first 6 mo of life. Am J Clin Nutr (2015) 102(6):1381-8. doi: 10.3945/ajcn.115.115451

17. Ballard O, Morrow AL. Human milk composition: nutrients and bioactive factors. Pediatr Clin North Am (2013) 60(1):49-74. doi: 10.1016/ j.pcl.2012.10.002

18. Battersby AJ, Gibbons DL. The gut mucosal immune system in the neonatal period. Pediatr Allergy Immunol (2013) 24(5):414-21. doi: 10.1111/pai.12079

19. Bode L. Human milk oligosaccharides: prebiotics and beyond. Nutr Rev (2009) 67 Suppl 2:S183-91. doi: 10.1111/j.1753-4887.2009.00239.x

20. Aakko J, Kumar H, Rautava S, Wise A, Autran C, Bode L, et al. Human milk oligosaccharide categories define the microbiota composition in human colostrum. Benef Microbes (2017) 8(4):563-7. doi: 10.3920/BM2016.0185

21. Ardeshir A, Narayan NR, Mendez-Lagares G, Lu D, Rauch M, Huang Y, et al. Breast-fed and bottle-fed infant rhesus macaques develop distinct gut microbiotas and immune systems. Sci Transl Med (2014) 6(252):252ra120 doi: 10.1126/scitranslmed.3008791

22. Azad MB, Konya T, Maughan H, Guttman DS, Field CJ, Chari RS, et al. Gut microbiota of healthy Canadian infants: profiles by mode of delivery and infant diet at 4 months. CMAJ (2013) 185(5):385-94. doi: 10.1503/cmaj.121189

23. Bergstrom A, Skov TH, Bahl MI, Roager HM, Christensen LB, Ejlerskov KT, et al. Establishment of intestinal microbiota during early life: a longitudinal, explorative study of a large cohort of Danish infants. Appl Environ Microbiol (2014) 80(9):2889-900. doi: 10.1128/AEM.00342-14

24. Brink LR, Matazel K, Piccolo BD, Bowlin AK, Chintapalli SV, Shankar K, et al. Neonatal Diet Impacts Bioregional Microbiota Composition in Piglets Fed Human Breast Milk or Infant Formula. J Nutr (2019) 149(12):2236-46. doi: $10.1093 / \mathrm{jn} / \mathrm{nxz} 170$

25. Davis EC, Wang M, Donovan SM. The role of early life nutrition in the establishment of gastrointestinal microbial composition and function. Gut Microbes (2017) 8(2):143-71. doi: 10.1080/19490976.2016.1278104

26. Al-Sheikh H. Effect of lactoferrin and iron on the growth of human pathogenic Candida species. Pak J Biol Sci (2009) 12(1):91-4. doi: 10.3923/pjbs.2009.91.94

27. Andersson Y, Lindquist S, Lagerqvist C, Hernell O. Lactoferrin is responsible for the fungistatic effect of human milk. Early Hum Dev (2000) 59(2):95-105. doi: 10.1016/s0378-3782(00)00086-4

28. Arnold D, Di Biase AM, Marchetti M, Pietrantoni A, Valenti P, Seganti L, et al. Antiadenovirus activity of milk proteins: lactoferrin prevents viral infection. Antiviral Res (2002) 53(2):153-8. doi: 10.1016/s0166-3542(01)00197-8

29. Autran CA, Schoterman MH, Jantscher-Krenn E, Kamerling JP, Bode L. Sialylated galacto-oligosaccharides and 2'-fucosyllactose reduce necrotising enterocolitis in neonatal rats. Br J Nutr (2016) 116(2):294-9. doi: 10.1017/ S0007114516002038

30. Bode L, Kuhn L, Kim HY, Hsiao L, Nissan C, Sinkala M, et al. Human milk oligosaccharide concentration and risk of postnatal transmission of HIV through breastfeeding. Am J Clin Nutr (2012) 96(4):831-9. doi: 10.3945/ajcn.112.039503

31. Cilieborg MS, Bering SB, Ostergaard MV, Jensen ML, Krych L, Newburg DS, et al. Minimal short-term effect of dietary 2'-fucosyllactose on bacterial colonisation, intestinal function and necrotising enterocolitis in preterm pigs. Br J Nutr (2016) 116(5):834-41. doi: 10.1017/S0007114516002646

32. Berding K, Wang M, Monaco MH, Alexander LS, Mudd AT, Chichlowski M, et al. Prebiotics and Bioactive Milk Fractions Affect Gut Development, Microbiota and Neurotransmitter Expression in Piglets. J Pediatr Gastroenterol Nutr (2016) 63(6):688-97. doi: 10.1097/MPG.0000000000001200

33. Mudd AT, Alexander LS, Berding K, Waworuntu RV, Berg BM, Donovan SM, et al. Dietary Prebiotics, Milk Fat Globule Membrane, and Lactoferrin Affects Structural Neurodevelopment in the Young Piglet. Front Pediatr 4:4:4. doi: 10.3389/fped.2016.00004

34. Thompson RS, Roller R, Mika A, Greenwood BN, Knight R, Chichlowski M, et al. Dietary Prebiotics and Bioactive Milk Fractions Improve NREM Sleep, Enhance REM Sleep Rebound and Attenuate the Stress-Induced Decrease in Diurnal Temperature and Gut Microbial Alpha Diversity. Front Behav Neurosci 10:240. doi: 10.3389/fnbeh.2016.00240

35. O’Reilly D, Dorodnykh D, Avdeenko NV, Nekliudov NA, Garssen J, Elolimy AA, et al. Perspective: The Role of Human Breast-Milk Extracellular Vesicles in Child Health and Disease. Adv Nutr (2020) 12(1):59-70. doi: 10.1093/ advances/nmaa094

36. Zonneveld MI, van Herwijnen MJC, Fernandez-Gutierrez MM, Giovanazzi A, Marit de Groot A, Kleinjan M, et al. Human milk extracellular vesicles target nodes in interconnected signalling pathways that enhance oral epithelial barrier function and dampen immune responses. J Extracellular Vesicles (2021) 10:e12071. doi: 10.1002/jev2.12071

Conflict of Interest: The authors declare that the research was conducted in the absence of any commercial or financial relationships that could be construed as a potential conflict of interest.

Copyright (c) 2021 Yeruva, Munblit and Collado. This is an open-access article distributed under the terms of the Creative Commons Attribution License (CC BY). The use, distribution or reproduction in other forums is permitted, provided the original author(s) and the copyright owner(s) are credited and that the original publication in this journal is cited, in accordance with accepted academic practice. No use, distribution or reproduction is permitted which does not comply with these terms. 